\title{
Anteroposterior radiograph of the right shoulder
}

Label $\mathrm{C}$ in this Endgames quiz points to the coracoid process of the scapula (BMJ 2015;350:h901, doi:10.1136/bmj.h901). The answer should have listed this, rather than "coronoid process of the ulna," as was published.
Cite this as: BMJ 2015;350:h1104

๑ BMJ Publishing Group Ltd 2015 